\title{
Patient-orientated longitudinal study of multiple sclerosis in south west England (The South West Impact of Multiple Sclerosis Project, SWIMS) 1: protocol and baseline characteristics of cohort
}

\author{
John P Zajicek ${ }^{1 *}$, Wendy M Ingram', Jane Vickery', Siobhan Creanor ${ }^{2}$, Dave E Wright ${ }^{2}$, Jeremy C Hobart ${ }^{1}$
}

\begin{abstract}
Background: There is a need for greater understanding of the impact of multiple sclerosis (MS) from the perspective of individuals with the condition. The South West Impact of MS Project (SWIMS) has been designed to improve understanding of disease impact using a patient-centred approach. The purpose is to (1) develop improved measurement instruments for clinical trials, (2) evaluate longitudinal performance of a variety of patientreported outcome measures, (3) develop prognostic predictors for use in individualising drug treatment for patients, particularly early on in the disease course.

Methods: This is a patient-centred, prospective, longitudinal study of multiple sclerosis and clinically isolated syndrome (CIS) in south west England. The study area comprises two counties with a population of approximately 1.7 million and an estimated 1,800 cases of MS. Self-completion questionnaires are administered to participants every six months (for people with MS) or 12 months (CIS). Here we present descriptive statistics of the baseline data provided by 967 participants with MS.
\end{abstract}

Results: Seventy-five percent of those approached consented to participate. The male:female ratio was 1.00:3.01 ( $\mathrm{n}=$ 967). Average (standard deviation) age at time of entry to SWIMS was 51.6 (11.5) years $(n=961)$ and median (interquartile range) time since first symptom was 13.3 (6.8 to 24.5$)$ years $(n=934)$. Fatigue was the most commonly reported symptom, with $80 \%$ of participants experiencing fatigue at baseline. Although medication use for symptom control was common, there was little evidence of effectiveness, particularly for fatigue. Nineteen percent of participants were unable to classify their subtype of MS. When patient-reported subtype was compared to neurologist assessment for a sample of participants $(n=396)$, agreement in disease sub-type was achieved in $63 \%$ of cases. There were 836 relapses, reported by 931 participants, in the twelve months prior to baseline. Twenty-three percent of the relapsingremitting group and $12 \%$ of the total sample were receiving disease-modifying therapy at baseline.

Conclusions: Demographics of this sample were similar to published data for the UK. Overall, the results broadly reflect clinical experience in confirming high symptom prevalence, with relatively little complete symptom relief.

Participants often had difficulty in defining MS relapses and their own MS type.

\section{Background}

The South-West Impact of Multiple Sclerosis study (SWIMS) is a longitudinal cohort study from the perspective of people with MS. This paper outlines the

\footnotetext{
* Correspondence: john.zajicek@phnt.swest.nhs.uk

${ }^{1}$ Clinical Neurology Research Group, Peninsula College of Medicine and Dentistry, University of Plymouth, UK

Full list of author information is available at the end of the article
}

rationale, methods and baseline results from the SWIMS cohort.

Multiple sclerosis (MS) is a complex and unpredictable disease with potential considerable impact on daily living, both for people with the condition and their carers. In order to develop and test new treatments in the context of clinical trials, there is a need for greater understanding of its impact, particularly from the 
perspective of individuals with the condition. Although people with MS have identified research into symptom relief as a high priority, there are relatively few effective symptomatic treatments, and many clinical trials of symptomatic treatments have been disappointingly negative. One reason for this may be that current methods for measuring disease impact are inadequate, and the relationship between symptoms, impairment and disability is not fully understood. In addition, measurement instruments often demonstrate limitations. For example, although fatigue is one of the most commonly reported symptoms in people with MS, and there are several scales purporting to measure the concept of fatigue, in clinical studies results using different fatigue scales may not strongly correlate with each other [1]. Given such limitations of the available measurement instruments it may not be surprising that few significant treatment effects are identified in clinical trials.

When attempting to evaluate disease impact, changes have generally been defined as objectively as possible, usually from the perspective of the neurologist, using clinical signs derived from neurological examination. There are several problems associated with this approach, including subjective interpretation of signs in a complex condition, as well as difficulties in detecting change over time. Another issue illustrating disease complexity lies in the way in which relapses are measured. Most clinical trials define relapses in terms of persistence of symptoms and signs, usually supported by changes on neurological examination. Yet we know that the frequency of changes on cranial magnetic resonance imaging (MRI) greatly exceeds the number of relapses supported by changes on neurological examination, and patients often report greater variability in their condition than can usually be confirmed by signs on neurological examination $[2,3]$. There is very little available information about relapses from the patient perspective, and even less data on the reliability of such information.

In trying to measure the impact of MS, to understand the natural history of MS, and establish the effectiveness of disease-modifying treatments, scales such as the Expanded Disability Status Scale (EDSS) [4] have become established as the most widely used "objective" means of measuring disease course. The EDSS is implemented by neurologists and has many accepted limitations, yet virtually all natural history studies have used the EDSS. A lack of responsiveness, amongst other limitations of the EDSS, means that clinical trials involving progressive MS patients are usually three years in duration, which can lead to a risk of patient drop-out. This may result in reduced statistical power to obtain an answer to the research question, such as occurred in the recent PrOMISe study [5]. In response to the recognised limitations of the EDSS, other instruments such as the MS Functional Composite [6] and the patient-reported MS Impact Scale-29 [7] have been developed and recommended for incorporation into clinical trials. Responsive patient-orientated rating scales have the potential to provide data which are sensitive to changes in disease. Such scales could therefore be used to model disease progression, in part to inform clinical trial methodology and also to provide relevant prognostic information for people early in the disease course. A more refined approach to providing prognostic information, from data derived over shorter periods, may enable patients and health care professionals to make betterinformed decisions with regard to risk and benefit of emerging treatments. However, there are very little longitudinal data available based on these newer instruments, thus little data on which to model disease progression and to use in performing power calculations for clinical trials. Therefore there remains a need to evaluate patient-reported rating scale performance over time.

Although there have been studies evaluating prevalence of certain common symptoms such as pain, fatigue and tremor, with limited investigation of longitudinal change over time [8-10], there has been little systematic evaluation of symptoms and how they change over time, and few studies of the relationship between prevalent symptoms and other aspects of disease impact. There remains a need to understand the impact of symptoms on disease progression.

SWIMS therefore has three major aims: 1) to facilitate a better understanding of disease impact from the patient perspective, in order to develop improved measurement instruments for clinical trials and clinical practice, 2) to evaluate longitudinal performance of a variety of commonly used, patient-reported outcome measures, 3) to collect, analyse, and model patientorientated longitudinal data in order to evaluate prognostic predictors and facilitate more individualised treatment in future patients, particularly early in the disease course.

Here we present summaries of the baseline data provided by the first 967 participants to consent to SWIMS.

\section{Methods \\ Study Area}

The SWIMS cohort is drawn from Devon and Cornwall - two counties which form a sea-bordered peninsula in south west England, covering $10,270 \mathrm{~km}^{2}$ in area. The study area is situated at latitude 50.78 , longitude -3.00 , at the most easterly point and latitude 50.12 , longitude -5.53 , at the most westerly point. 
The population of approximately 1.67 million people [11] is served by five acute hospitals and three neurology centres, each with its own rehabilitation centre. Devon and Cornwall are ideally suited to this type of longitudinal cohort study as the population is relatively stable and migration rates are low[12,13].

In our prevalence study of MS in an area within the study region, we found a rate of 118 per 100,000, in a population of 341,796[5]. Based on this prevalence, we estimate the number of cases of MS in the SWIMS study region to be approximately $1,800[6]$.

\section{Eligibility criteria}

Inclusion criteria: clinical diagnosis of MS by either McDonald or Poser criteria, or diagnosis of clinically isolated syndrome (CIS), aged 18 years and over, and resident in Devon or Cornwall. Exclusion criterion: severe cognitive impairment such that the patient is unable to provide informed consent.

\section{Recruitment}

The study was approved by the Cornwall and Plymouth Research Ethics Committee and the South Devon Research Ethics Committee, and adheres to the Data Protection Act 1998. SWIMS commenced in August 2004, and continues to recruit new participants. Followup is expected to continue until 2019.

Patients with established MS or CIS are invited to take part by one of the following routes:

1) Patients attending neurology outpatient clinics are approached by their neurology team.
2) Patients identified from review of hospital case notes are approached by their neurologist.

3) A survey of General Practitioners within Devon and Cornwall was conducted in which GPs were asked to approach eligible patients known to them who had not previously been approached by other routes.

4) Patient self-referral, in response to public awareness campaigns involving the Multiple Sclerosis Society and local media, or via information on the SWIMS website.

Informed consent is obtained to retain the data provided and to review previous medical records in order to verify diagnosis.

\section{Data collection}

Consented MS patients are asked to complete questionnaire booklets twice per year. The full details of the questionnaire can be found at http://www.pms.ac.uk/ $\mathrm{cnrg} /$ swims, but briefly data collection includes: type of MS (with examples of MS sub-types represented graphically in order to assist in classification, similar to Bamer et al and Lublin and Reingold [14,15]), relapses, symptoms, medication, investigations, contact with health and social care professionals, and whether the participant feels that he/she has deteriorated in the previous six months. The questionnaire booklet contains the following definition of a relapse: "a worsening of existing neurological symptoms which lasts for at least 48 hours, or the appearance of a new neurological symptom which lasts for at least 48 hours". A range of validated questionnaires is included (Table 1). In addition, the

Table 1 Validated instruments included in questionnaire booklets

\begin{tabular}{|c|c|c|c|c|c|}
\hline & $\begin{array}{l}\text { MS Baseline } \\
\text { Questionnaire }\end{array}$ & $\begin{array}{l}\text { MS 6-Monthly Follow- } \\
\text { Up Questionnaire } \\
\text { Version A* }\end{array}$ & $\begin{array}{l}\text { MS 6-Monthly Follow- } \\
\text { Up Questionnaire } \\
\text { Version B* }\end{array}$ & $\begin{array}{l}\text { CIS Baseline } \\
\text { Questionnaire }\end{array}$ & $\begin{array}{l}\text { CIS 12-Monthly } \\
\text { Follow-Up } \\
\text { Questionnaire }\end{array}$ \\
\hline EuroQol [27] & $\checkmark$ & $\checkmark$ & & $\checkmark$ & $\checkmark$ \\
\hline Fatigue Severity Scale [28] & $\checkmark$ & $\checkmark$ & & & \\
\hline $\begin{array}{l}\text { Functional Assessment of MS } \\
\text { (modified 44-items scale) [29] }\end{array}$ & $\checkmark$ & & $\checkmark$ & & \\
\hline $\begin{array}{l}\text { General Health Questionnaire-30 } \\
\text { [30] }\end{array}$ & $\checkmark$ & $\checkmark$ & & $\checkmark$ & $\checkmark$ \\
\hline $\begin{array}{l}\text { Medical Outcomes Study Short } \\
\text { Form 36-Item Health Study (version } \\
\text { 2) [31] }\end{array}$ & $\checkmark$ & & $\checkmark$ & $\checkmark$ & $\checkmark$ \\
\hline $\begin{array}{l}\text { MS Disease Impact Scale-29 } \\
\text { (version 2) [7] }\end{array}$ & $\checkmark$ & $\checkmark$ & & & \\
\hline $\begin{array}{l}\text { MS Neuropsychological Screening } \\
\text { Questionnaire [32] }\end{array}$ & $\checkmark$ & & $\checkmark$ & & \\
\hline MS Walking Scale (version 2) [33] & $\checkmark$ & $\checkmark$ & & & \\
\hline Postal Barthel Index [34] & $\checkmark$ & & $\checkmark$ & & \\
\hline
\end{tabular}


baseline questionnaire includes items concerning the onset of MS, e.g. date of diagnosis.

Consented CIS patients complete similar questionnaires once per year, with data collected on episodes of inflammation, symptoms, treatments, investigations, contact with health professionals and whether the diagnosis of CIS has changed. Three validated questionnaires are also included (Table 1). Patients with CIS at baseline who are subsequently diagnosed with MS are switched to the six-monthly MS data collection schedule.

In addition to the patient-completed questionnaires, EDSS is assessed for patients attending neurology outpatient clinics at one of the neurology centres, but no specific clinic attendance is organised to evaluate relapse information. SWIMS is therefore very much patientorientated, complemented by information from neurological appointments where available.

To examine the reliability of patient-reported MS subtype, we conducted a comparison of patient-reported MS subtype with neurologist evaluation using retrospective case note evaluation. All participants were asked in the baseline questionnaire to indicate which type of MS they considered that they had. Case notes for the first 396 participants by surname were reviewed by the project coordinator or neurologist for this purpose.

\section{Data management}

Anonymised data are input to a bespoke Microsoft SQL Server 2005 database, using a double data entry system to eliminate data entry errors. Data are then exported to statistical packages including SPSS (version 15) and Minitab (version 15) for summarizing and statistical analysis.

\section{Data analysis}

Data from 967 baseline questionnaires completed by participants with MS were collated and summarised using descriptive statistics to provide a comprehensive profile of this cohort.

\section{Results and Discussion}

\section{Recruitment and follow-up}

Figure 1 illustrates the disposition of MS patients approached to participate between August 2004 and April 2008 as well as follow-up rates during this time period. Within the same period, 40 invitations were sent to patients with CIS, of whom 35 (87.5\%) consented to participate. Two participants with CIS were subsequently diagnosed with MS, and a further four participants with CIS were lost to follow-up (due to moving outside the study area).

Approximately $75 \%$ of those provided with information about the project between August 2004 and April 2008 consented to take part, which we consider to be a reasonable recruitment rate for this type of study. However, it is still important to understand why people chose not to take part. Reasons given to the neurologist for not taking part included a preference not to be reminded of the diagnosis of MS, particularly in the early stages of the condition.

The predominant source of recruits $(63 \%$ of those recruited) was the consultant-led outpatient neurology clinic. A further $21 \%$ had been approached following review of the hospital notes, $10 \%$ were self-referrals, and $6 \%$ had been approached by their General Practitioner on behalf of the research team.

Median duration of follow-up is 2.0 years $(\mathrm{n}=1023)$, with initial recruits to SWIMS having completed four years of follow-up. Eighty-eight people (8\% of those consented) were lost to follow-up to the end of April 2008: 47 (4\% of those consented) decided to withdraw, 25 (2\%) died, 15 (1\%) moved out of the study area, 1 (< $1 \%)$ had the diagnosis of MS revoked. The most common reasons for self-withdrawal were: "in poor health" and "questionnaires too difficult/burdensome". Questionnaire completion is consistently high, with $92 \%$ of the 5075 booklets sent to participants up to the end of April 2008 returned to the research team. The questionnaire return rates of around $90 \%$ are remarkable, and are being maintained by providing regular newsletters about the project and an appreciation by people with MS that the information being collected will lead to improved understanding and treatments in due course. The large sample size also provides reassurance of limited potential bias. Participant retention in long-term studies is a crucial issue when considering current methods of testing treatments in progressive MS. We are currently exploring methods of maximising retention to SWIMS, including use of internet data capture and on-line questionnaire completion.

Recruitment and data collection will continue for the foreseeable future, and we expect the information derived from this study to become increasingly useful over time. Because the project is a longitudinal study of patient-reported outcomes, we have excluded people with severe cognitive impairment, as we do not have validated methods for patient-reported data under these circumstances. This may inevitably lead to a degree of bias in the overall results in epidemiological terms, but this design will be able to address the aims of the project, namely to enable a better understanding of disease impact, to evaluate and improve on patient-reported outcomes, and to develop alternative prognostic models.

\section{Baseline data for MS patients Participant demographics}

Seventy five percent of the study sample $(\mathrm{n}=967)$ was female, a ratio of 3.01:1.00. The age range at time of 


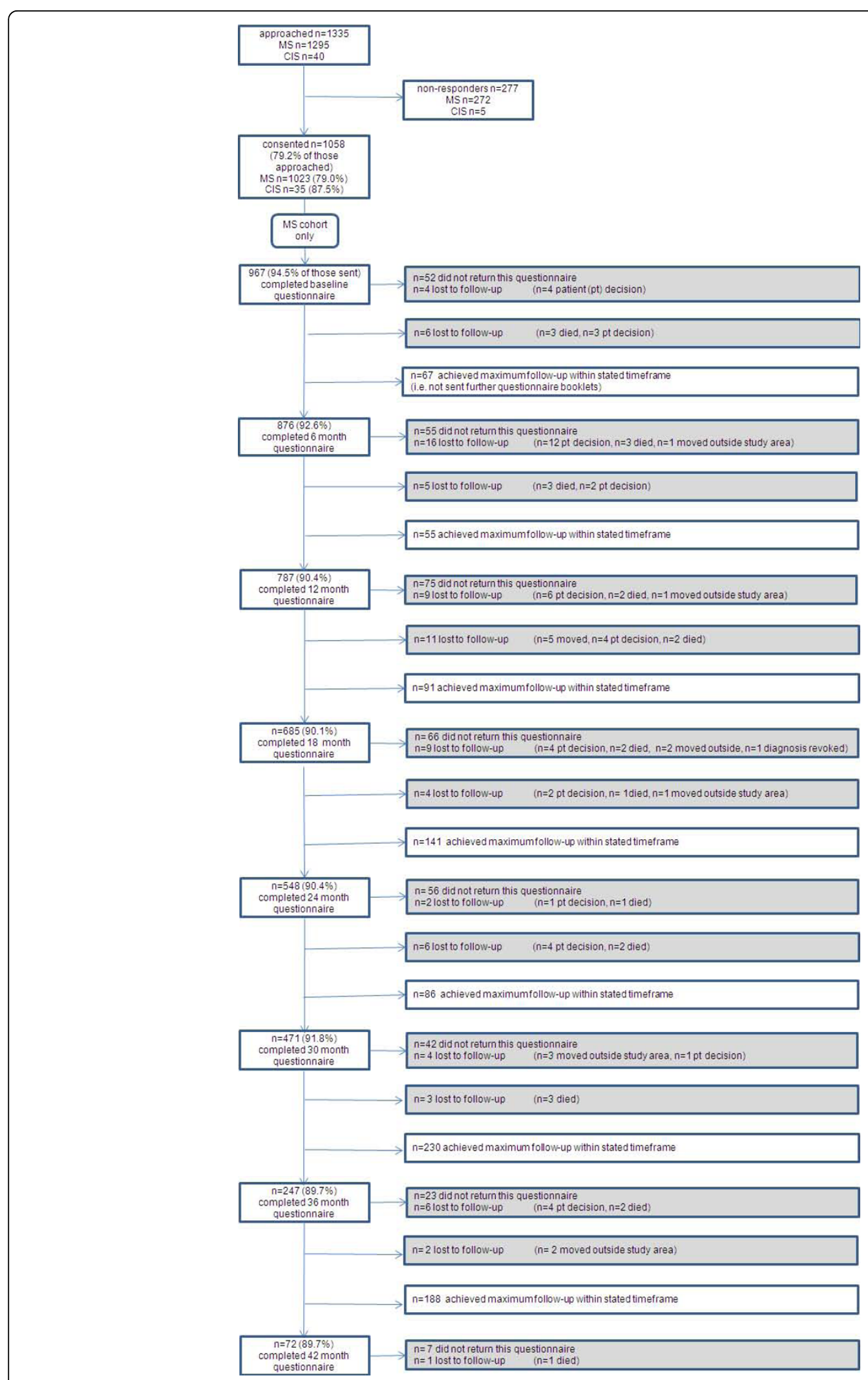

Figure 1 Disposition of individuals approached to participate between August 2004 and April 2008. 
entry to SWIMS was 18.4 to 83.4 years, with a mean (standard deviation) of $51.6(11.5)$ years $(\mathrm{n}=961)$. Mean (standard deviation) age at disease onset, i.e. patientreported date of first MS symptom, was 35.4 (10.8) years $(\mathrm{n}=902)$. The median (inter-quartile range) time since first symptom of MS to time of entry to SWIMS was $13.3(6.8$ to 24.5$)$ years $(\mathrm{n}=934)$ and median (inter-quartile range) time since diagnosis was 9.9 (2.9 to 15.9$)$ years $(\mathrm{n}=921)$.

Diagnosis was reported to have been assisted using MRI in $84 \%$ of the sample. Thirty-five percent of the participants had MRI together with lumbar puncture and evoked potentials, whereas $8 \%$ of participants had been diagnosed on clinical grounds only. The demographics of the SWIMS sample were similar to other surveys of MS in regions of the UK, as reviewed by Fox et al [16].

\section{Type of MS}

Thirty six percent of participants reported that they had relapsing-remitting MS (RRMS) at time of entry to SWIMS, 21\% had primary progressive MS (PPMS), 19\% had secondary progressive (SPMS), $3 \%$ had a benign type and $21 \%$ did not know which type. When compared to neurologist assignment of MS subtype, agreement was achieved in $63 \%$ of the 396 cases reviewed. Cohen's kappa statistic was 0.48: a "moderate" level of agreement according to Altman[17]. The 95\% confidence interval for kappa was 0.42 to 0.54 .

The most common differences amongst the remaining cases were (a) when the participant was unsure of MS type and the neurologist was able to define subtype $(\mathrm{n}=$ $58,15 \%$ of total), (b) where the participant felt they were in the RR phase, but the neurologist felt they were progressive $(\mathrm{n}=31,8 \%)$, (c) when there was disagreement between PPMS and SPMS $(\mathrm{n}=28,7 \%)$. and $(\mathrm{d})$ when patients identified themselves as having progressive disease, but the neurologist had assigned RRMS $(\mathrm{n}=12,3 \%)$.

Defining MS subtypes can be an inexact science, even from the perspective of the neurologist. For example, in progressive disease, when an individual may present in middle age with a history of one or more possible neurological events earlier in life, it can be difficult to define
Table 2 Patient-reported number of relapses in twelve months prior to baseline: percentage of participants experiencing relapse(s) by MS type

\begin{tabular}{|c|c|c|c|c|c|c|}
\hline \multirow[b]{2}{*}{ MS Type } & \multicolumn{6}{|c|}{$\begin{array}{l}\text { Number of relapses in last twelve } \\
\text { months }\end{array}$} \\
\hline & 0 & 1 & 2 & 3 & 4 & Don't know \\
\hline Benign $(n=28)$ & 54 & 39 & 0 & 0 & 0 & 7 \\
\hline Relapsing-Remitting ( $\mathrm{n}=345$ ) & 23 & 35 & 19 & 9 & 6 & 8 \\
\hline Primary Progressive $(n=182)$ & 65 & 13 & 6 & 2 & 3 & 12 \\
\hline Secondary Progressive $(n=178)$ & 33 & 34 & 9 & 7 & 3 & 14 \\
\hline Don't Know $(n=173)$ & 30 & 23 & 15 & 7 & 3 & 22 \\
\hline All $(n=931)$ & 36 & 28 & 13 & 7 & 4 & 13 \\
\hline
\end{tabular}

Data for MS subtype or the number of relapses or both were missing for 36 participants.

subtype with certainty. Similarly, when an individual has had a diagnosis of RRMS and starts to acquire increasing disability, the precise definition of onset of secondary progression becomes blurred. Our experience is that patients often have difficulty in defining their own disease course, and the current levels of uncertainty are not unexpected.

\section{Relapse data}

Participants were asked to give details on any relapses that they had had in the previous twelve months. The number of relapses, by patient-reported MS type, is summarised in Table 2. Overall, 36\% of participants were relapse-free in the previous twelve months. Across all participants, the mean (standard deviation) number of relapses was 0.9 (1.1) per year, whilst the mean (standard deviation) number of relapses in those reporting at least one relapse in the previous twelve months was 1.8 (1.0) per year.

The use of steroids in association with relapses, time off work due to relapses, hospitalisation and limitations in everyday activities associated with relapses are summarised in Table 3 . Of all the 835 relapses in the previous twelve months, 157 (19\%) resulted in no time off work, 61 (7\%) resulted in less than one week off work, 38 (5\%) resulted in one to two weeks off work and 106 $(18 \%)$ resulted in more than two weeks away from work. For 394 relapse incidents (47\%) the individual was not

Table 3 Patient-reported impact of relapse(s) in twelve months prior to baseline: percentage of relapses by relapse number

\begin{tabular}{lccccc}
\hline Relapse Number & $\begin{array}{c}\text { Oral } \\
\text { steroids }\end{array}$ & $\begin{array}{c}\text { IV } \\
\text { steroids }\end{array}$ & $\begin{array}{c}\text { Time off } \\
\text { work }\end{array}$ & Hospitalised & $\begin{array}{c}\text { Limitations to } \\
\text { everyday activities }\end{array}$ \\
\hline $1^{\text {st }}$ or only relapse $(n=477)$ & 19 & 16 & 25 & 15 & 78 \\
\hline $2^{\text {nd }}(n=221)$ & 14 & 11 & 24 & 7 & 76 \\
\hline $3^{\text {rd }}(n=99)$ & 9 & 7 & 19 & 5 & 73 \\
\hline $4^{\text {th }}(n=38)$ & 5 & 8 & 18 & 8 & 63 \\
\hline All relapses $(n=835)$ & 16 & 13 & 24 & 11 & 76 \\
\hline
\end{tabular}


working. Data on work impact was missing from 79 relapses $(10 \%)$. In total, $2 \%$ of relapses were treated with both oral and intravenous steroids, $12 \%$ with intravenous steroids only and $14 \%$ were treated with oral steroids only (at various doses).

Data on MS relapse can be notoriously difficult to interpret, with the presence of daily symptom variation and "pseudorelapse", in which a variety of mechanisms other than an increase in disease activity is responsible for symptom deterioration. Although many clinical trials have used the original Poser criterion [18] for relapse, of at least twenty-four hours of neurological deterioration, we opted for the more stringent definition of at least forty-eight hours of change in symptoms. This more stringent definition has previously been used in clinical trials (for example in Jacobs et al [19]) and it was felt to be more appropriate in the context of patient selfreport, in order to minimise the potential for reporting of pseudorelapse.

Previous data on relapse frequency with retrospective assessment in cross sectional studies provide a figure of $<0.5 /$ year, whereas prospective evaluation of relapses provides a higher figure, of between 0.5 and 1.0 relapse/ year (reviewed in Confavreux and Compston[20]). Data from the present SWIMS cohort would therefore be consistent with other studies in which more formal evaluation of relapses has taken place, and suggests that patient report could be a valid and less resource intensive method for relapse assessment. Further work is needed to investigate this assumption and also to evaluate the impact of relapse on both overall disease course and from the patient perspective.

Not unexpectedly, some patients who classified themselves as either PPMS or SPMS continued to report having relapses, with the mean (standard deviation) relapse frequency being higher in the SPMS group (0.8 (1.1) per year) compared to the PPMS group (0.4 (0.9) per year). This is consistent with other data from PPMS populations; a significant minority (28\% in one study[21]) of patients with PPMS reported an apparent relapse at some time during the course of the disease[22].

Although around three quarters of relapses were associated with limitation of everyday activities, only $11 \%$ of relapses resulted in hospital admission, which is consistent with an increasing tendency to use oral steroids rather than intravenous steroids. Not surprisingly, considerable time was lost off work due to relapse. Although previous studies have considered employment, e.g. Kobelt et al [23], very little work has been done on the full economic impact of relapse when adjusted for loss of earnings. The present SWIMS cohort sample is likely to have less bias than some previous work in this regard. For example, although Kobelt's study [23] included questionnaire data from over 13,000 people with MS, administered through the national MS Society, this represented a response rate of only $19 \%$. The SWIMS data provide some insight into relapse impact in the era of disease modifying drugs, but much more work is needed to develop rigorous ways of evaluating relapse impact at all stages of the disease. The data would suggest that there is a need to provide a better definition of relapse from the patient perspective, without resorting to the EDSS or neurological examination. This may have implications for the use of disease modifying treatments, and further work investigating the relationship between patient-identified relapse and longterm disability would be useful.

\section{Symptoms}

Participants were asked to indicate their current symptoms, if any. Table 4 lists the percentages of all participants reporting symptoms at the time of completion of the baseline questionnaire, by patient-reported MS type.

It is not surprising that fatigue was the most commonly reported symptom across all participants. Regarding subtypes of MS, sensory symptoms were slightly more common than fatigue in the benign disease subgroup, and in both types of progressive disease (primary and secondary) balance difficulties were slightly more common than fatigue. Memory problems were reported by about $60 \%$ of patients, with the only major difference between subtypes being that benign disease was associated with less memory trouble (35\%). Similarly, concentration difficulties were reported by around $50 \%$ of the participants, with few differences between subtypes except benign MS where the reported prevalence was $38 \%$.

\section{Medication}

Participants were asked to indicate which medications they were currently taking, or had taken in the last twelve months. Of the total SWIMS participants $(\mathrm{n}=967)$, $18.1 \%$ were currently taking or had previously taken some form of disease modifying therapy (including betainterferon, glatiramer acetate, azathioprine, alemtuzemab, mitoxantrone and cyclophosphamide). Within the RRMS group $31 \%(n=347)$ were currently receiving or had previously received disease modifying medication. The percentages currently on this type of medication were $23 \%$ of the RR group and $12 \%$ of the total sample. The commonest disease modifying drugs in use were one of the forms of beta-interferon and glatiramer acetate $(22 \%$ of RR group and $11 \%$ of the total sample).

In order to obtain a picture of the possibly unmet need for symptom treatment in MS, we report symptoms and associated medication use in Table 5 . Although 769 patients ( $80 \%$ of the cohort) experienced fatigue, only 3 people were taking amantadine or modafanil and were without fatigue. Fifty people (7\%) were taking one of these medicines and continued to have fatigue. Among the large percentage of people with 
Table 4 Symptoms reported at baseline: percentage of participants by self-reported MS type

\begin{tabular}{|c|c|c|c|c|c|}
\hline & $\begin{array}{c}\text { All } \\
(\mathrm{n}=967)\end{array}$ & $\begin{array}{c}\text { Benign } \\
(\mathrm{n}=29)\end{array}$ & $\begin{array}{l}\text { Relapsing-remitting } \\
(\mathrm{n}=347)\end{array}$ & $\begin{array}{l}\text { Primary progressive } \\
(\mathrm{n}=202)\end{array}$ & $\begin{array}{c}\text { Secondary progressive } \\
(\mathrm{n}=184)\end{array}$ \\
\hline Fatigue & 80 & 38 & 80 & 83 & 83 \\
\hline Poor balance & 75 & 35 & 64 & 90 & 89 \\
\hline Any pain, including visual pain & 70 & 35 & 67 & 77 & 76 \\
\hline Any pain (not visual) & 69 & 35 & 65 & 76 & 75 \\
\hline Muscle weakness & 64 & 28 & 53 & 82 & 80 \\
\hline Problems with memory & 57 & 35 & 58 & 57 & 59 \\
\hline Pins and needles/tingling & 56 & 45 & 59 & 54 & 55 \\
\hline Decreased or worsening mobility & 56 & 10 & 35 & 81 & 76 \\
\hline Muscle stiffness & 54 & 21 & 48 & 64 & 67 \\
\hline Muscle spasms & 53 & 17 & 44 & 66 & 67 \\
\hline Sensory loss/numbness & 53 & 28 & 53 & 49 & 65 \\
\hline Loss of dexterity & 52 & 21 & 41 & 65 & 70 \\
\hline Urinary urgency & 49 & 38 & 44 & 49 & 57 \\
\hline Muscular pain & 49 & 28 & 42 & 57 & 57 \\
\hline Problems with concentration & 49 & 38 & 50 & 47 & 54 \\
\hline Urinary frequency & 48 & 38 & 45 & 52 & 53 \\
\hline Constipation & 44 & 28 & 40 & 48 & 52 \\
\hline Difficulties with co-ordination & 43 & 14 & 33 & 56 & 56 \\
\hline Emotional lability & 42 & 28 & 46 & 38 & 39 \\
\hline Joint pain & 40 & 21 & 36 & 45 & 42 \\
\hline Feeling anxious & 35 & 31 & 31 & 39 & 39 \\
\hline Urinary incontinence & 30 & 24 & 19 & 39 & 41 \\
\hline Depression & 30 & 21 & 28 & 31 & 30 \\
\hline Urinary hesitancy & 29 & 14 & 24 & 31 & 39 \\
\hline Weight gain & 28 & 10 & 23 & 33 & 32 \\
\hline Blurred vision & 27 & 14 & 29 & 25 & 28 \\
\hline Sexual problems & 27 & 14 & 23 & 29 & 36 \\
\hline Tremor & 26 & 7 & 19 & 35 & 33 \\
\hline Burning pain & 25 & 21 & 23 & 24 & 29 \\
\hline Shooting pain & 23 & 10 & 21 & 23 & 26 \\
\hline Swallowing difficulties & 21 & 7 & 13 & 27 & 28 \\
\hline Speech problems & 21 & 7 & 16 & 26 & 25 \\
\hline Faecal incontinence & 13 & 7 & 8 & 15 & 22 \\
\hline Other pain & 13 & 10 & 12 & 13 & 14 \\
\hline Double vision & 12 & 10 & 10 & 15 & 17 \\
\hline Weight loss & 10 & 14 & 6 & 10 & 16 \\
\hline Diarrhoea & 10 & 10 & 9 & 8 & 9 \\
\hline Painful vision & 9 & 4 & 10 & 8 & 12 \\
\hline Colour desaturation & 8 & 4 & 10 & 5 & 7 \\
\hline Pressure sores & 4 & 0 & 2 & 8 & 6 \\
\hline
\end{tabular}

A total of 205 participants did not know their MS type, or did not report an MS type.

symptoms of bladder dysfunction, $26 \%$ were taking some associated oral medication. Five percent of people with bladder symptoms had obtained complete symptom relief, as indicated by the number of participants without current symptoms of bladder dysfunction but currently taking medication indicated for bladder dysfunction.

Over $70 \%$ of the SWIMS cohort experience pain of some type, most commonly treated with paracetamol or ibuprofen, both available without prescription in the 
Table 5 Symptoms and associated medications use

\begin{tabular}{lrr}
\hline Symptom & $\begin{array}{r}\text { Number (\%) of } \\
\text { participants }\end{array}$ & $\begin{array}{r}\text { Associated } \\
\text { medicatio }\end{array}$ \\
& with current symptom &
\end{tabular}

Number (\%) of participants

with current symptom

\begin{tabular}{|c|c|c|c|c|c|}
\hline & & & $\begin{array}{r}\text { currently taking } \\
\text { associated } \\
\text { medication }\end{array}$ & $\begin{array}{r}\text { not currently } \\
\text { taking, } \\
\text { but previously } \\
\text { taken, } \\
\text { associated } \\
\text { medication }\end{array}$ & $\begin{array}{r}\text { currently taking } \\
\text { associated medication }\end{array}$ \\
\hline \multirow[t]{2}{*}{ Fatigue } & $769(80)$ & Amantadine & $33(4)$ & $35(5)$ & $2(1)$ \\
\hline & & Modafinil & $17(2)$ & $16(2)$ & $1(1)$ \\
\hline \multirow[t]{5}{*}{ Bladder } & $756(78)$ & Desmopressin spray & $6(1)$ & $9(1)$ & 0 \\
\hline & & $\begin{array}{l}\text { Desmopressin } \\
\text { tablets }\end{array}$ & $5(1)$ & $3(0)$ & 0 \\
\hline & & Oxybutinin & $93(12)$ & $64(8)$ & $6(3)$ \\
\hline & & Tolterodine & $63(8)$ & $25(3)$ & $2(1)$ \\
\hline & & Trimethoprim & $27(4)$ & $35(5)$ & $2(1)$ \\
\hline \multirow[t]{7}{*}{$\begin{array}{l}\text { Pain (including visual } \\
\text { pain) }\end{array}$} & $681(71)$ & Amitriptyline & $123(18)$ & $85(12)$ & $19(7)$ \\
\hline & & Carbemazepine & $39(6)$ & $47(7)$ & $4(1)$ \\
\hline & & Co-codamol & $107(16)$ & $117(17)$ & $8(3)$ \\
\hline & & Gabapentin & $83(12)$ & $48(7)$ & $5(2)$ \\
\hline & & Ibruprofen & $127(19)$ & $194(28)$ & $28(10)$ \\
\hline & & Nabilone & $6(1)$ & $7(1)$ & 0 \\
\hline & & Paracetamol & $188(28)$ & $193(28)$ & $28(10)$ \\
\hline \multirow[t]{7}{*}{ Spasticity } & $672(70)$ & Baclofen pump & $6(1)$ & $1(0)$ & $2(1)$ \\
\hline & & Baclofen tablets & $163(24)$ & $78(12)$ & $17(6)$ \\
\hline & & Botulinum toxin & $2(<1)$ & $0(0)$ & 0 \\
\hline & & Clonazepam & $24(4)$ & $9(1)$ & $2(1)$ \\
\hline & & Dantrolene & $7(1)$ & $5(1)$ & $1(<1)$ \\
\hline & & Diazepam & $26(4)$ & $64(10)$ & $4(1)$ \\
\hline & & Tizanidine & $45(7)$ & $16(2)$ & $2(1)$ \\
\hline \multirow[t]{7}{*}{$\begin{array}{l}\text { Pain (excluding visual } \\
\text { pain) }\end{array}$} & $670(69)$ & Amitriptyline & $123(18)$ & $86(13)$ & $19(6)$ \\
\hline & & Carbemazepine & $39(6)$ & $47(7)$ & $4(1)$ \\
\hline & & Co-codamol & $104(16)$ & $117(17)$ & $11(4)$ \\
\hline & & Gabapentin & $82(12)$ & $48(7)$ & $6(2)$ \\
\hline & & Ibruprofen & $126(19)$ & $189(28)$ & $29(10)$ \\
\hline & & Nabilone & $6(1)$ & $6(1)$ & 0 \\
\hline & & Paracetamol & $185(28)$ & $192(29)$ & $31(11)$ \\
\hline \multirow[t]{4}{*}{ Depression } & $484(50)$ & Citalopram & $34(7)$ & $15(3)$ & $3(1)$ \\
\hline & & Fluoxetine & $47(10)$ & $33(7)$ & $14(3)$ \\
\hline & & Paroxetine & $9(2)$ & $12(3)$ & $7(2)$ \\
\hline & & Sertraline & $13(3)$ & $3(1)$ & $3(1)$ \\
\hline \multirow[t]{2}{*}{ Constipation } & $421(44)$ & Fybogel & $32(8)$ & $76(18)$ & $8(2)$ \\
\hline & & Senna & $65(15)$ & $98(23)$ & $7(1)$ \\
\hline Sexual problems & $256(27)$ & Viagra & $34(13)$ & $16(6)$ & $9(1)$ \\
\hline $\begin{array}{l}\text { Sexual problems (males } \\
\text { only) }\end{array}$ & $129\left(54^{1}\right)$ & Viagra & $34(26)$ & $15(12)$ & $9(1)$ \\
\hline Tremor & $248(26)$ & Propranolol & $10(4)$ & $7(3)$ & $5(1)$ \\
\hline
\end{tabular}

\footnotetext{
${ }^{1} 54 \%$ of males in study sample.
} 
Table 6 Contact with specialists in twelve months prior to baseline: percentage of participants

\begin{tabular}{|c|c|c|c|c|c|}
\hline & $\begin{array}{c}\text { Not seen/ } \\
\text { Not applicable }\end{array}$ & Once & 2 to 4 times & $\geq 5$ times & $\begin{array}{c}\text { Total number } \\
\text { of responses }\end{array}$ \\
\hline Chiropodist (or podiatrist) & 86 & 4 & 6 & 4 & 811 \\
\hline Clinical Psychologist & 97 & 1 & 1 & $<1$ & 795 \\
\hline Continence Advisor/Nurse & 77 & 11 & 11 & 2 & 827 \\
\hline District Nurse & 87 & 3 & 3 & 7 & 810 \\
\hline Dietician & 96 & 2 & 2 & $<1$ & 799 \\
\hline $\mathrm{GP}$ & 24 & 20 & 38 & 18 & 896 \\
\hline MS Specialist Nurse & 54 & 25 & 19 & 2 & 857 \\
\hline Neurologist & 28 & 44 & 26 & 1 & 904 \\
\hline Occupational Therapist & 75 & 10 & 11 & 4 & 823 \\
\hline Ophthalmologist & 78 & 17 & 5 & 1 & 825 \\
\hline Pain management service & 96 & 2 & 2 & 1 & 804 \\
\hline Physiotherapist & 54 & 10 & 19 & 17 & 851 \\
\hline Rehabilitation Doctor & 97 & 2 & 1 & $<1$ & 803 \\
\hline Respite or Rehabilitation Unit (admitted for a period of respite care) & 93 & 4 & 3 & $<1$ & 803 \\
\hline Social Worker & 88 & 5 & 6 & 2 & 812 \\
\hline Speech Therapist & 93 & 5 & 2 & $<1$ & 805 \\
\hline
\end{tabular}

UK. About $10 \%$ of the cohort who did not report having pain, continue to take such simple analgesics.

Symptoms of spasticity were also present in around $70 \%$ of the cohort, and about one third of people affected were taking some medication for this, with single figure percentages obtaining complete symptom relief (using the assumption given above for bladder dysfunction).

\section{Contact with health and social care specialists}

Participants were asked to indicate whether they had seen any specialists about their MS in the last twelve months and if so, how often (Table 6). Access to specialist services will vary both within and between counties. Asking about service contact, relapses and symptoms enables a broad picture to be created of the impact of MS on individuals and the ability of health services to deal with that impact. Considerable service demands are placed on primary care, even though each General Practitioner may only expect to have two to four patients with MS on their list. This is evident even when specialist nurses and neurologists with an interest in MS are available. At the other end of the scale, considering the prevalence of cognitive symptoms and pain, contact with clinical psychology and the pain management services is surprisingly low. It is difficult to know whether this reflects poor availability of services or problems in care pathways. Although there are some recommendations concerning the ratio of specialist nurses to population, there is comparatively little available data on casemix for individual health specialists, making health planning difficult. Once again, there is a need for more work on the comparative success of treatments and support made available by each of the range of individuals that comprises the multidisciplinary team.

\section{Conclusions}

Here we describe the rationale for SWIMS and report the baseline characteristics of a cohort of 967 people with MS. Overall, the data broadly reflect clinical experience in confirming high symptom prevalence with relatively little complete symptom relief. Establishing effective treatments for these symptoms must start with a full appreciation of all aspects of symptom impact.

SWIMS is enabling new scales to be developed (e.g. the MS Spasticity Scale, MSSS-88 [24]), and the performance of other scales to be evaluated (including the Fatigue Severity Scale [25], the General Health Questionnaire-30 [26], and the MS Walking Scale). Further qualitative work will be necessary in order to inform aspects of symptom impact useful for the creation of new measurement instruments.

\section{Acknowledgements}

This study was funded by The Multiple Sclerosis Society of Great Britain and Northern Ireland, The Peninsula Medical School Foundation and the UK NIHR Comprehensive Clinical Research Network.

\section{Author details}

${ }^{1}$ Clinical Neurology Research Group, Peninsula College of Medicine and Dentistry, University of Plymouth, UK. ²Department of Medical Statistics, University of Plymouth, UK.

\section{Authors' contributions}

JZ conceived of the concept and design of the study. WI participated in the coordination of the study. JV and $\mathrm{JH}$ participated in the design of the study. SC performed the statistical analysis. DW participated in the design of the study and performed the statistical analysis. All authors participated in 
drafting the manuscript, and all authors read and approved the final manuscript.

\section{Competing interests}

The authors declare that they have no competing interests.

Received: 17 November 2009 Accepted: 7 October 2010

Published: 7 October 2010

\section{References}

1. Giovannoni G, Thompson AJ, Miller DH, Thompson EJ: Fatigue is not associated with raised inflammatory markers in multiple sclerosis. Neurology 2001, 57(4):676-681.

2. Isaac C, Li DK, Genton M, Jardine C, Grochowski E, Palmer M, Kastrukoff LF Oger J, Paty DW: Multiple sclerosis: a serial study using MRI in relapsing patients. Neurology 1988, 38(10):1511-1515.

3. Thompson AJ, Kermode AG, MacManus DG, Kingsley DP, Kendall BE, Moseley IF, McDonald WI: Pathogenesis of progressive multiple sclerosis. Lancet 1989, 1(8650):1322-1323.

4. Kurtzke JF: Rating neurologic impairment in multiple sclerosis: an expanded disability status scale (EDSS). Neurology 1983, 33(11):1444-1452.

5. Wolinsky JS, Narayana PA, O'Connor P, Coyle PK, Ford C, Johnson K, Miller A, Pardo L, Kadosh S, Ladkani D: Glatiramer acetate in primary progressive multiple sclerosis: results of a multinational, multicenter, double-blind, placebo-controlled trial. Ann Neurol 2007, 61(1):14-24.

6. Fischer JS, Rudick RA, Cutter GR, Reingold SC: The Multiple Sclerosis Functional Composite Measure (MSFC): an integrated approach to MS clinical outcome assessment. National MS Society Clinical Outcomes Assessment Task Force. Mult Scler 1999, 5(4):244-250.

7. Hobart JC, Riazi A, Lamping DL, Fitzpatrick R, Thompson AJ: Improving the evaluation of therapeutic interventions in multiple sclerosis: development of a patient-based measure of outcome. Health Technology Assessment 2004, 8(9).

8. Brochet B, Deloire MS, Ouallet JC, Salort E, Bonnet M, Jove J, Petry KG: Pain and quality of life in the early stages after multiple sclerosis diagnosis: a 2-year longitudinal study. Clin J Pain 2009, 25(3):211-217.

9. Hadjimichael $\mathrm{O}$, Vollmer T, Oleen-Burkey M: Fatigue characteristics in multiple sclerosis: the North American Research Committee on Multiple Sclerosis (NARCOMS) survey. Health Qual Life Outcomes 2008, 6:100.

10. Pittock SJ, McClelland RL, Mayr WT, Rodriguez M, Matsumoto JY: Prevalence of tremor in multiple sclerosis and associated disability in the Olmsted County population. Mov Disord 2004, 19(12):1482-1485.

11. Office of National Statistics: Sub-regional resident population for mid2007.[http://www.statistics.gov.uk/downloads/theme_population/KPVS342007/KPVS2007.pdf].

12. Office of National Statistics: Internal Migration by Local Authorities in England and Wales.[http://www.statistics.gov.uk/statbase/Product.asp? $v \operatorname{lnk}=15148]$.

13. Office of National Statistics: Total International Migration (TIM) tables: 1991-latest.[http://www.statistics.gov.uk/statbase/Product.asp?vlnk=15053]

14. Bamer AM, Cetin K, Amtmann D, Bowen JD, Johnson KL: Comparing a self report questionnaire with physician assessment for determining multiple sclerosis clinical disease course: a validation study. Mult Scler 2007, 13(8):1033-1037

15. Lublin FD, Reingold SC: Defining the clinical course of multiple sclerosis: results of an international survey. National Multiple Sclerosis Society (USA) Advisory Committee on Clinical Trials of New Agents in Multiple Sclerosis. Neurology 1996, 46(4):907-911.

16. Fox CM, Bensa S, Bray I, Zajicek JP: The epidemiology of multiple sclerosis in Devon: a comparison of the new and old classification criteria. Journal of Neurology, Neurosurgery and Psychiatry 2004, 75(1):56-60.

17. Altman DG: Practical statistics for medical research. London: Chapman and Hall 1991.

18. Poser CM, Paty D, Scheinburg L: New diagnostic criteria for multiple sclerosis: guidelines for research protocols. Ann Neurol 1983, 13:227-231.

19. Jacobs LD, Cookfair DL, Rudick RA, Herndon RM, Richert JR, Salazar AM, Fischer JS, Goodkin DE, Granger CV, Simon JH, et al: Intramuscular interferon beta-1a for disease progression in relapsing multiple sclerosis. The Multiple Sclerosis Collaborative Research Group (MSCRG). Ann Neurol 1996, 39(3):285-294.
20. Confavreux C, Compston A: The natural history of multiple sclerosis. In McAlpine's Multiple Sclerosis. Philadelphia: Churchill Livingstone Elsevier, Forth 2006, 183-269.

21. Cottrell DA, Kremenchutzky M, Rice GP, Koopman WJ, Hader W, Baskerville J, Ebers GC: The natural history of multiple sclerosis: a geographically based study. 5. The clinical features and natural history of primary progressive multiple sclerosis. Brain 1999, 122(4):625-639.

22. Miller DH, Leary SM: Primary-progressive multiple sclerosis. Lancet Neurol 2007, 6(10):903-912.

23. Kobelt G, Berg J, Lindgren P, Kerrigan J, Russell N, Nixon R: Costs and quality of life of multiple sclerosis in the United Kingdom. Eur J Health Econ 2006, 7(2):S96-104.

24. Hobart JC, Riazi A, Thompson AJ, Styles IM, Ingram W, Vickery PJ, Warner M Fox PJ, Zajicek JP: Getting the measure of spasticity in multiple sclerosis: the Multiple Sclerosis Spasticity Scale (MSSS-88). Brain 2006, 129(1):224-234

25. Baron R, Ingram WM, Warner M, Vickery PJ, Wright DE, Zajicek JP, Hobart JC: Meaningless statistics and the illusion of fatigue. Journal of Neurology Neurosurgery and Psychiatry 2006, 77(1):133.

26. Warner $M$, Baron $R$, Ingram WM, Vickery PJ, Reilly S, Wright DE, Zajicek JP, Hobart JC: Does the GHQ leave room for change? Journal of Neurology Neurosurgery and Psychiatry 2006, 77(1):134.

27. EuroQol G: EuroQol - a new facility for the measurement of healthrelated quality of life. Health Policy 1990, 16:199-208.

28. Krupp LB, LaRocca NG, Muir-Nash J, Steinberg AD: The fatigue severity scale. Application to patients with multiple sclerosis and systemic lupus erythematosus. Arch Neurol 1989, 46(10):1121-1123.

29. Cella D: Validation of the Functional Assessment of Multiple Sclerosis quality instrument. Neurology 1996, 47:129-139.

30. Goldberg D: A user's guide to the General Health Questionnaire. United Kingdom: Windsor NFER-Nelson 1988.

31. Jenkinson C: Assessment of the SF-36 version 2 in the UK. Journal of Epidemiology Community Health 1999, 53:46-50.

32. Benedict RH, Munschauer F, Linn R, Miller C, Murphy E, Foley F, Jacobs L: Screening for multiple sclerosis cognitive impairment using a selfadministered 15-item questionnaire. Mult Scler 2003, 9(1):95-101.

33. Hobart JC: Measuring the impact of multiple sclerosis on walking ability: the 12 item MS Walking Scale (MSWS-12). Neurology 2003, 60:31-36.

34. Mahony F: The Fatigue Severity Scale. Application to patients with multiple sclerosis and systemic lupus erythematous. Archives Neurology 1965, 46(10):1121-1123.

Pre-publication history

The pre-publication history for this paper can be accessed here: http://www.biomedcentral.com/1471-2377/10/88/prepub

doi:10.1186/1471-2377-10-88

Cite this article as: Zajicek et al:: Patient-orientated longitudinal study of multiple sclerosis in south west England (The South West Impact of Multiple Sclerosis Project, SWIMS) 1: protocol and baseline characteristics of cohort. BMC Neurology 2010 10:88.

\section{Submit your next manuscript to BioMed Central and take full advantage of:}

- Convenient online submission

- Thorough peer review

- No space constraints or color figure charges

- Immediate publication on acceptance

- Inclusion in PubMed, CAS, Scopus and Google Scholar

- Research which is freely available for redistribution 